\title{
A PROCEDURE \\ FOR EVALUATING \\ ENVIRONMENTAL IMPACT
}

Copy is PUBIIC PROPRTTY and is not

to be romoved from tho of ictal filag:

(R. S. Sup. Val.

W

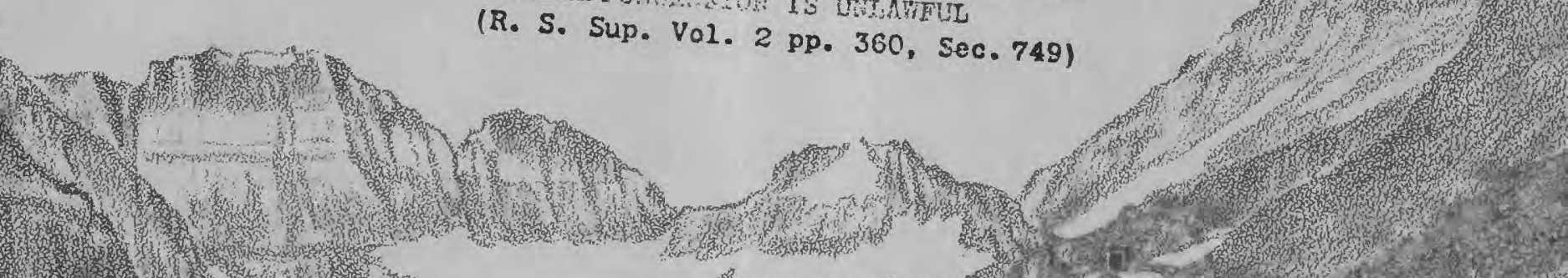

(2)

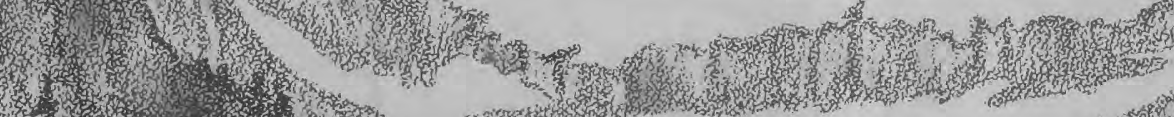

t)

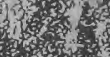

\section{7.}

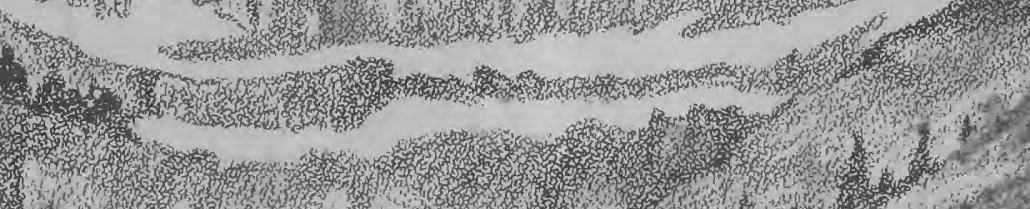

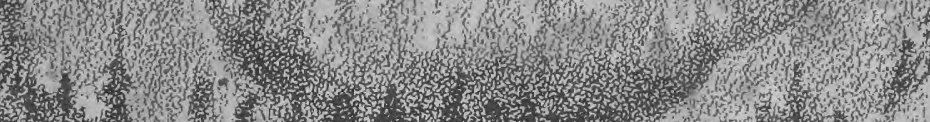





\section{A Procedure \\ for Evaluating \\ Environmental Impact}

By Luna B. Leopold, Frank E. Clarke,

Bruce B. Hanshaw, and James R. Balsley

GEOLOGICAL SURVEY CIRCULAR 645

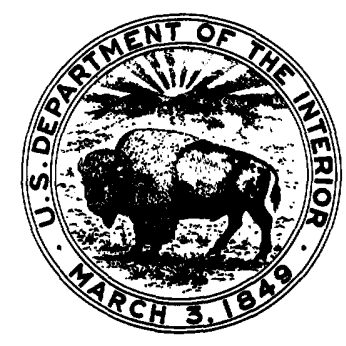


United States Department of the Interior ROGERS C. B. MORTON, Secretary

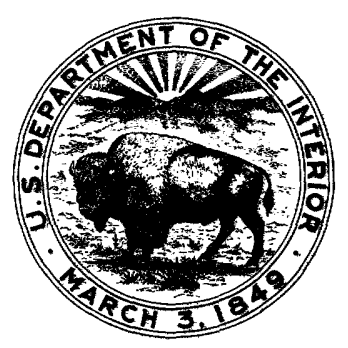

Geological Survey

W. A. Radlinski, Acting Director

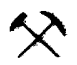




\section{FOREWORD}

Man cannot survive on this planet without utilizing its natural resources prudently. Every human action affects the world around us in some degree and the full effect is difficult to assess because of complex relations among living and nonliving things. Under the circumstances one can neither expect to restore the entire past nor preserve the entire present for future generations. However all can and should strive for proper balance between resource development and maintenance of pleasant surroundings.

The Environmental Quality Act of 1969 and the reports on environmental assessment that it requires are aimed at insuring such a balanced approach. To be effective we must provide a system for relating large numbers of actions and environmental factors and for placing value judgments on impacts which are difficult to quantify.

At my request the Geological Survey has developed an information matrix system that is described and modeled in this Circular. It is published with the thought that it will serve as a useful guide for environmental impact reporting and as a systematic reference. Those who share with us the desire to retain or improve the quality of our environment will recognize that this report is a sincere but still preliminary effort to fill an interim need. We hope that suggestions from others will improve this framework.

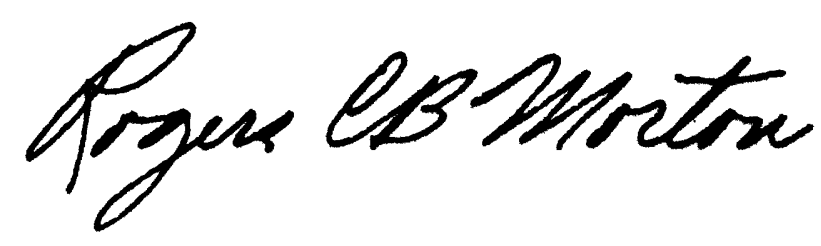

ROGERS C. B. MORTON

Secretary of the Interior 



\title{
A Procedure for Evaluating Environmental Impact
}

\author{
By Luna B. Leopold, Frank E. Clarke, Bruce B. Hanshaw, and James R. Balsley
}

\section{PREAMBLE}

In a recent article in "Science" discussing the Environmental Policy Act of 1969, Gillette (1971) states "The law's instructions for preparing an impact report apparently are not specific enough to insure that an agency will fully, or even usefully, examine the environmental effects of the projects it plans." This report contains a procedure that may assist in developing uniform environmental impact statements. The Department of the Interior and the Council on Environmental Quality will appreciate comments on the procedure here proposed.

The heart of the system is a matrix which is general enough to be used as a reference checklist or a reminder of the full range of actions and impacts on the environment that may relate to proposed actions. The marked matrix also serves as an abstract of the text of the environmental assessment to enable the many reviewers of impact reports to determine quickly what are considered to be the significant impacts and their relative importance as evaluated by the originator of the impact report.

Many exhaustive studies of the use of matrices for environmental studies are now being undertaken. (See Sorensen, 1971.) This comparatively simple system is intended as a guide for the many people who are faced with the evaluation and preparation of environmental impact reports before the results of these studies have been completed. It should be borne in mind that there is presently no uniformity in approach or agreement upon objectives in an impact analysis and this generalized matrix is a step in that direction.

The procedure does not limit the development of detail in any specific aspect of the environment; a separate expanded matrix for any environmental aspect can easily be developed within the framework provided.

\section{INTRODUCTION}

In any proposal for construction or development, it is the usual practice, both from the standpoint of engineering and economics, to prepare an analysis of the need for the development and the relationship between its monetary costs and monetary benefits. More re- cently, society has recognized that in addition to these customary economic analyses and discussions of need, there should be a detailed assessment of the effect of a proposed development on the environment and thus its ecological, separate from its monetary, benefits and costs; put together, these assessments comprise an Environmental Impact Statement. The preparation of a Statement should be done by a team of physical and social scientists and engineers; likewise, reviews of statements will generally require an interdisciplinary team effort.

The Environmental Policy Act of 1969 directs all agencies of the Federal Government to "identify" and develop methods and procedures which will insure that presently unquantified environmental amenities and values are given appropriate consideration in decisionmaking along with economic and technical considerations". The Council on Environmental Quality, in furtherance of Section 102 of the Act, has set forth guidelines for the preparation of the required environmental statements. It is recommended in these guidelines that the second item to be included in the statement is "the probable impact of the proposed action on the environment".

This circular suggests an approach to accomplish that specific requirement by providing a system for the analysis and numerical weighting of probable impacts. This type of analysis does not produce an overall quantitative rating but portrays many value judgments. It can also serve as a guide in preparing the statement called for under Section $102(2)$ (c) of the Act. A primary purpose is to insure that the impact of alternative actions is evaluated and considered in project planning. 


\section{DEVELOPMENT OF AN ACTION PROGRAM; GENERALIZED PROCEDURE}

Evaluating the environmental impact of an action program or proposal is a late step in a series of events which can be outlined in the following manner. Figure 1 is a flow chart of the recommended sequence of events which result in an environmental impact statement. The sequence is discussed briefly below and that portion which deals with impact assessment is expanded in more detail later in the text:

A. A statement of the major objective sought by the proposed project.

B. The technologic possibilities of achieving the objective are analyzed.

C. One or more actions are proposed for achieving the stated objective. The alternative plans which were considered as practicable ways of reaching the objective are spelled out in the proposal.

D. A report which details the characteristics and conditions of the existing environment prior to the proposed action is prepared. In some cases, this report may be incorporated as part of the engineering proposal.

E. The principal engineering proposals are finalized as a report or series of separate reports, one for each plan. The plans ordinarily have analyses of monetary benefits and costs.

F. The proposed plan of action, usually the engineering report, together with the report characterizing the present environment, sets the stage for evaluating the environmental impact of the proposal. If alternative ways of reaching the objective are proposed in $\mathrm{C}$ and if alternative engineering plans are detailed in the engineering report, separate environmental impact analyses must deal with each alternative. If only one proposal is made in the engineering report, it is still necessary to evaluate environmental impacts.

The environmental impact analyses require the definition of two aspects of each action which may have an impact on the environment. The first is the definition of the magnitude of the impact upon specific sectors of the environment. The term magnitude is used in the sense of degree, extensiveness, or scale. For example, highway development will alter or affect the existing drainage pattern and may thus have a large magnitude of impact on the drainage. The second is a weighting of the degree of $\mathrm{im}$ portance (i.e. significance) of the particular action on the environmental factor in the specific instance under analysis. Thus the overall importance of impact of a highway on a particular drainage pattern may be small because the highway is very short or because it will not interfere significantly with the drainage. Depending upon the thoroughness and scope of the report inventorying existing environmental conditions, the analysis of magnitude of impact, though in some details subjective, can nevertheless be factual and unbiased. It should not include weights which express preference or bias.

The importance of each specific environmental impact must include consideration of the consequences of changing the particular condition on other factors in the environment. Again, the adequacy of the report under D would affect the objectivity in the assignment of the values for specific environmental conditions. Unlike magnitude of impact, which can be more readily evaluated on the basis of facts, evaluation of the importance of impact generally will be based on the value judgment of the evaluator. The numerical values of magnitude and importance of impact reflect the best estimates of pertinence of each action.

G. The text of the environmental impact report should be an assessment of the impacts of the separate actions which comprise the project upon various factors of the environment and thus provide justification for the determinations presented in F. Each plan of action should be analyzed independently.

H. The Environmental Impact Statement should conclude with a summation and recommendations. This section should discuss the relative merits of the various proposed actions and alternative engineering plans and explain the rationale behind the final choice of action and the plan for achieving the stated objective. 


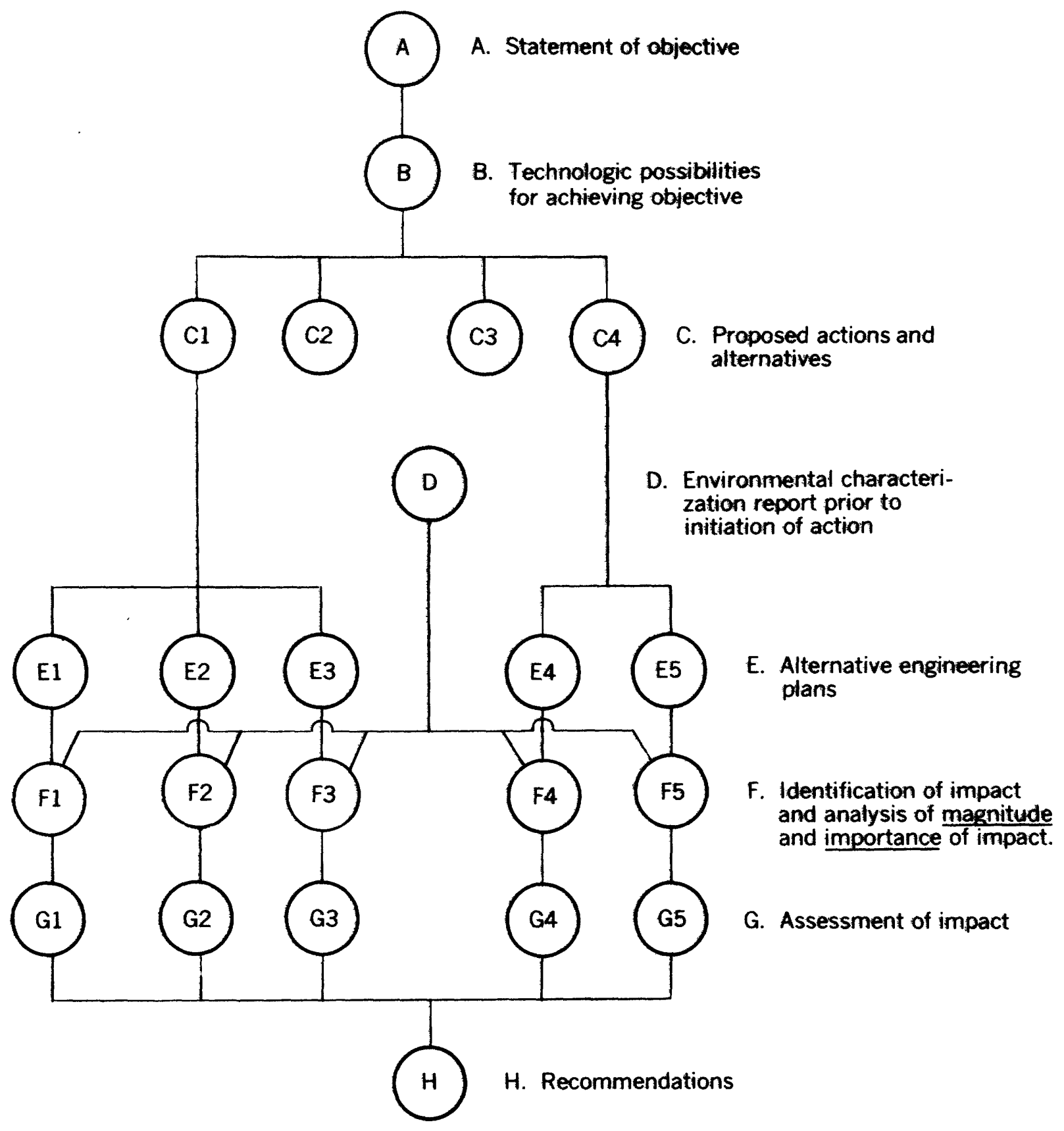

Figure 1.-Flow chart for development of action programs. 


\section{THE ENVIRONMENTAL IMPACT STATEMENT}

A complete environmental impact statement consists of four basic items:

1. A complete analysis of the need for the proposed action. This would include parts $A, B$, and $\mathrm{C}$ of the Generalized Procedures ;

2. An informative description of the environment to be involved, including a careful consideration of the boundaries of a project. For example, every drainage crossed by a highway can be affected at that point of crossing but may also be affected downstream as well owing to erosion. Therefore, these effects beyond the right-of-way should be described in part D of the Generalized Procedures;

3. A discussion of the pertinent details of the proposed action-part $\mathrm{E}$ of the Generalized Procedures;

4. An assessment of the probable impacts of the variety of specific aspects of the proposed action upon the variety of existing environmental elements and factors-parts $F$ and $G$ of the Generalized Procedures-and a summary or recommendation-part $\mathrm{H}$-which would include the rationale supporting the selected plan of action.

The analysis of need, item (1) above, should be a justification which considers the full range of values to be derived, not simply the usual cost-benefit analysis. It should include a discussion of the overall objectives and of possible alternatives to meet them.

The characterization of the existing environment, item (2) above, should be a detailed description of the existing environmental elements and factors, with special emphasis on those rare or unique aspects, both good and bad, that might not be common to other similar areas. It should provide sufficient information to permit an objective evaluation of the environmental factors which could be affected by proposed actions. The description should include all the factors which together make up the ecosystem of the area. The vertical margin of the enclosed matrix can be used as a checklist in preparing this section.

The details of proposed action, item (3) above, should include discussion of possible alternative engineering methods or approaches to accomplish the proposed development (item 1). This should be done in sufficient detail so that all actions that.may have impact upon the environment (item 2) can be checked. The horizontal margin of the matrix can be used as a checklist in preparing this section.

The environmental impact assessment, item (4) above, should consist of three basic elements:

a. A listing of the effects on the environment which would be caused by the proposed development, and an estimate of the magnitude of each.

b. An evaluation of the importance of each of these, effects.

c. The combining of magnitude and importance estimates in terms of a summary evaluation.

In preparing this circular, it is not the intent to deal at length with items (1) through (3), and it is assumed that generalized procedures for their preparation are commonly followed since these items have been incorporated in many engineering feasibility studies and benefit-cost analyses of past projects. Rather, the primary intent is to focus on the new requirement and, therefore to address primarily the preparation of item (4) - the environmental impact assessment.

\section{ENVIRONMENTAL IMPACT ASSESSMENT} MATRIX

The analysis embodied in $a, b$, and $c$ above is made with a matrix (Plate 1) including on one axis the actions which cause environmental impact and on the other existing environmental conditions that might be affected. This provides a format for comprehensive review to remind the investigators of the variety of interactions that might be involved. It helps the planners to identify alternatives which might lessen impact. The number of actions listed horizontally in this sample matrix is 100 and the vertical list of environmental characteristics contains 88 , which give a total of 8,800 possible interactions. Within such a matrix, only a few of the interactions would be likely to involve impacts of such magnitude and importance that they deserve comprehensive treatment. Although the items listed represent most of the basic actions and environmental factors likely to be involved in the full range of developments 
which require impact reporting, not all would apply to every project proposal. Even this large matrix may not contain all elements necessary to make a full analysis of every project proposal encountered. However, the coding and format are designed for easy expansion to include additional items. Preliminary trials suggest that the number of applicable interactions for a typical project analysis usually will be between 25 and 50 .

The most efficient way to use the matrix is to check each action (top horizontal list) which is likely to be involved significantly in the proposed project. Generally, only about a dozen actions will be important. Each of the actions thus checked is evaluated in terms of magnitude of effect on environmental characteristics on the vertical axis, and a slash is placed diagonally from upper right to lower left across each block which represents significant interaction. In marking the matrix, it is important to remember that actions may have major shortterm impact (for a year or so) which are ameliorated in a few years and thus of minor or negligible importance in a long time frame. Conversely, other actions with lesser initial impact may produce more significant and persistent secondary effects and, therefore, have major impact in a long time frame. In the text, which discusses the matrix, one should indicate whether he is assessing short-term or long-term impact. As an example, oil drilling rigs are commonly considered noisy and nonaesthetic but they are on location for short periods of time-generally one to six months per site, whereas untreated spoil banks may silt and acidify streams for many years after completion of a project.

In marking the boxes, unnecessary replication can be avoided by concentrating on first-order effects of specific actions. For example, "mineral processing" would not be marked as affecting "aquatic life", even if the waste products are toxic in aquatic environments. The aquatic impact would be covered under "emplacement of tailing", "spills and leaks", or other processing operations which may lead to degradation of aquatic habitat.

After all the boxes which represent possible impact have been marked with a diagonal line, the most important ones are evaluated individually. Within each box representing a significant interaction between an action and an environmental factor, place a number from 1 to 10 in the upper left-hand corner to indicate the relative magnitude of impact; 10 represents the greatest magnitude and 1, the least. In the lower right-hand corner of the box, place a number from 1 to 10 to indicate the relative importance of the impact; again 10 is the greatest.

As an example, assume that a particular engineering proposal recommends construction of highways and bridges. The proposed action is item II.B.d. on the matrix. "Highways and bridges" might have environmental impacts through effect on "erosion" and related "deposition and sedimentation", among other things. "Erosion" and "deposition-sedimentation" occur under the main heading "Physical and Chemical Characteristics of the Environment" on the left side (ordinate) of the matrix and in the horizontal rows I.A.4.b. and I.A.4.c., respectively.

In this example, it might be that bridges will cause an important amount of bank erosion, because geologic materials in the area are poorly consolidated. This may lead the investigator to mark the magnitude of impact of highways and bridges on erosion 6 or more. If, however, the streams involved already have high sediment loads and appear to be capable of carrying such loads without objectionable secondary effects, the effective importance of bridges through increased erosion and sedimentation might be considered relatively small and marked 1 or 2 in the lower righthand corner of the block. This would mean that while magnitude of impact is relatively high, the importance of impact is not great.

In the assessment of accidents (II, J) such as "spills and leaks", it would be desirable to have some guide which would be helpful in determining the probability and effect of accidents. In this matter, the inclusion of controls which would reduce the probability of an accident would lower the matrix entry to magnitude, but it would have no influence on the evaluation of importance of impact.

The next step is to evaluate the numbers which have been placed in the slashed boxes. 
At this point, it is convenient to construct a simplified or reduced matrix which consists of only those actions and environmental characteristics which have been identified as interacting. Special note may be taken of boxes with exceptionally high individual numbers, as by circling the box. Although not used in this circular, we have found it convenient, when comparing alternatives in an action program, to identify the beneficial impacts with + , because alternate action plans may have different degrees of both beneficial and possibly detrimental impacts. However, in most cases the preparer will consider all impacts to be potentially deleterious because all the + factors would have been covered in the engineering report. Other investigators may wish to devise their own numerical rating methods; hence, the marginal boxes of Plate I are simply titled "computations".

It must be emphasized that no two boxes on any one matrix are precisely equatable. Rather, the significance of high or low numbers for any one box only indicates the degree of impact one type of action may have on one part of the environment. If alternative actions are under consideration, and a separate matrix is prepared for each action, identical boxes in the two matrices will provide a numerical comparison of the environmental impact for the alternatives considered.

Assignment of numerical weights to the magnitude and importance of impacts should be, to the extent possible, based on factual data rather than preference. Thus, the use of a rating scheme such as the one suggested here discourages purely subjective opinion and requires the author of an environmental impact statement to attempt to quantify his judgment of probable impacts. The overall rating allows the reviewer to follow the originator's line of reasoning and will aid in identifying points of agreement and disagreement. The matrix, is in fact, the abstract for the text of the environmental assessment.

\section{TEXT}

The text of an environmental impact assessment should be a discussion of individual boxes marked with the larger numerical values for magnitude and importance. Additionally, those columns which cause a large number of actions to be marked, regardless of their numerical values, should be discussed in detail. Likewise, those elements of the environment (rows) which have relatively large numbers of boxes marked should be addressed. The discussion of these items should cover the following points as put forth in the Council on Environmental Quality's guidelines published in the Federal Register (1971):

(i) a description of the proposed action including information and technical data adequate to permit careful assessment of impact. (This has been covered as items $\mathrm{C}$ and $\mathrm{E}$ in fig. 1.)

(ii) the probable impact of the proposed action on the environment

(iii) any probable adverse environmental effects which cannot be avoided

(iv) alternatives to the proposed action

(v) the relationship between local short-term uses of man's environment and the maintenance and enhancement of long-term productivity

(vi) any irreversible and irretrievable commitments of resources which would be involved in the proposed action should it be implemented, and

(vii) where appropriate, a discussion of problems and objections raised by other Federal, State, and local agencies and by private organizations and individuals in the review process and the disposition of the issues involved. This section may be added at the end of the review process in the final text of the environmental statement.

All of these points itemized above can be covered as part of a discussion of the matrix.

The text that accompanies the completed matrix should be primarily a discussion of the reasoning behind the assignment of numerical values for the magnitude of impact effects and their relative importance. The text should include a discussion of those actions which have significant impact and should not be diluted by discussions of obviously trivial side issues.

To be fully understandable, the discussion of the magnitude and importance of applicable impacts and responses will require some discussion in the text of the principal characteristics, physical and ecological, of the environ- 
ment itself and some of the important characteristics of the proposed action which govern its environmental impact. The environmental impact assessment thus relies on and refers to the data incorporated in items 1, 2, and 3 (p.4)the full description of the geography, physical setting, vegetation, climate, and other facts about the environment and the physical and engineering aspects of the proposed development. This explanation is inserted here to caution that the environmental impact assessment need not be burdened nor should it be padded with descriptions of the project and the environment per se. It should include only such details as are needed for evaluating the environmental impact. The completed environmental impact assessment, together with items (1), (2), and (3), comprises the finished Environmental Impact Statement; all four items are required for review purposes.

In order to test the usefulness of the matrix approach, a matrix for an actual proposed mineral extraction and processing operation has been prepared and included as an appendix. This example is solely a model used for demonstration purposes and is not intended to be an impact assessment of the example project. A brief synopsis of the justification, regional setting, and general plan of operation extracted from a report which covers items (1), (2), and (3) of an environmental impact statement is included. In addition, for each of the boxes with entries, there is a brief discussion of the impact rating including the reasoning behind the assignment of values.

\section{CONCLUDING STATEMENT}

Obviously, the wide variety of projects and actions have such differing impact on environmental factors that no scheme of impact assessment will be universally applicable. However, greatest need is not for a single and universally applicable assessment method, but rather for a simple way of summarizing which impacts are considered of greatest moment by the people making the assessment. Different assessors will seldom come to identical conclusions, but it would be useful to know the basis for the difference.
The advantage of a matrix is in its use as a checklist or reminder of the full range of actions and impacts. The proposed manner of using the matrix is aimed at separating as far as possible factual information on magnitude of each type impact from the more subjective evaluation of the importance of the impact, the latter involving preference or bias to some degree. This separation of fact from preference is highly desirable.

Finally, the matrix and suggested method of use is presented as a draft, subject to improvement, expansion, and change. Because it is impractical to circulate unpublished manuscripts widely, this manuscript is being submitted for review by potential users as a U.S. Geological Survey circular, a series used for tentative, incomplete, or preliminary statements.

The authors acknowledge with thanks the cooperation of Robert $H$. Twiss for sharing his experience in matrix construction and for his thoughtful review of this manuscript. The help furnished through discussion, manuscript revision, and suggestions by Elmer Baltz and George Davis is also gratefully acknowledged.

\section{APPENDIX: IMPACT ASSESSMENT OF A PHOSPHATE MINING LEASE BY MATRIX ANALYSIS}

A phosphate deposit estimated to include 80 million tons of crude ore of an average content of 8.7 percent $\mathrm{P}_{2} \mathrm{O}_{5}$ is located in Los Padres National Forest, Ventura County, California. The ore consists of sand-size pellets of phosphorite occurring in a sequence of sandstones and siltstones of late Miocene age. The beds crop out on hillslopes along a strike length of about 5 miles. The beds dip approximately $30^{\circ}$ north. The mineable beds are 90 feet thick with an overburden varying from 0 to 200 feet.

Application for a prospecting permit was made in February 1964, and a permit was granted in November 1964. A 3-year extension of the permit was approved in October 1966. The company made an application for a Preference Right Phosphate Lease in April 1969. The background material needed for the present analysis is contained in the company's report. Parts of the report are abstracted below for purposes of this circular. 
The regional environment.-The deposit occurs in a semiarid region receiving 23 inches of annual percipitation, most of which occurs in the period November through April. The principal drainage system in the area is Sespe Creek; its headwaters are about 5 miles west of the Lease Application. In its upper reaches, Sespe is an ephemeral stream. The proposed mining operation would be 2 miles north of the Sespe. Vegetation ranges from sparse to medium heavy, is of a chaparral type including oak, manzanita, and mountain mahogany, and with a low density ground cover of grass.

Access to the area is by means of California State Highway 33, a black-topped paved road which runs from Ventura to Bakersfield. The prospect is within one to two miles of this highway; present access is over a temporary unpaved road. To develop the property, about $11 / 2$ miles of permanent paved road would have to be built.

The region is sparsely settled. In a 5-mile radius of the proposed mine, there are six yearround residents plus 10 summer residences. The nearest towns are Meiners Oaks and Ojai, 25 miles to the south, and New Cuyama about 35 miles to the north.

General mining plans.-The ore crops out as a narrow band about 5 miles long. Test core drilling indicated that the rock is too unstable to support underground workings and the company proposes to develop the mine by open-pit methods. The strike is approximately perpendicular to the local stream channels which drain toward Sespe Creek. The small canyons cut across the ore zone every 2,000 to 3,000 feet along the strike. In order to prevent damage to the watershed, the company envisions a mining operation which would not dam or interrupt these channels. Therefore, over the life of the mining operation a series of open pits would be dug parallel to the strike and terminated short of the tributary valleys which cross the ore body. The dimensions of the proposed open pits will be determined by the interval between adjacent canyons. Pit width would be a function of the amount of overburden which could be removed economically. In the downdip direction, mining would extend only so far as economics of overburden removal would allow.
The planned open pit geometry is $\mathrm{V}$-shaped. One limb would follow the foot wall of the ore zone at approximately $30^{\circ}$ from the horizontal. The high wall would be cut at $45^{\circ}$ to the horizontal. Such a pit would be worked in a series of 20 -foot high benches running parallel to the strike.

Ore processing.-An ore-processing plant would be constructed at the mine site to crush the ore. After crushing, the phosphate would be leached out with acid. The resultant pregnant liquor would be neutralized with quicklime to precipitate dicalcium phosphate in a granular form.

The tailings from the leach process is quartz sand which would be washed, dewatered, and stored in the open pit areas where mining had been completed.

The phosphate in the form either of granular solids or liquid would be transported to market via trucks. The major raw materials required to be brought in are quicklime and sulphur, the latter being converted to sulphuric acid at the mine site. Water required for the processing is small and is to be supplied by a 1,000-foot deep well already drilled.

Watershed and environmental values.-There are two principal environmental values which require consideration in this area as well as many subsidiary ones. A primary consideration is the effect on the California condor, a rare and endangered species present in the general region. The second major consideration is location of the mine lease close to the center of a large block of National Forest land. Pertinent to the latter is the fact that the total lease, 2,434 acres, is small by comparison with the total Forest. The site is 15 miles east-southeast along the mountain ridge from the edge of the San Rafael Wilderness so that no designated wilderness lands are involved. However, the need for recreational use of undeveloped public lands in California to relieve population pressure is relatively great and any commercial operation in an undeveloped area would have an effect on such use.

The Sespe Condor Sanctuary, located in the National Forest, lies 15 miles to the east of the mining area. From this sanctuary, the condors are said to range along the crestline to 
the northwest, across the center of the whole National Forest area. The ordinary flight or soaring patterns for condors would pass through the general region of the proposed mine site. One condor nest, apparently now abandoned, has been noted a few miles west of the mining site. The other known condor nests all lie within the condor sanctuary.

Among the subsidiary environmental impacts which the mining operation might cause, a few are mentioned briefly below and are discussed in more detail in connection with the impact matrix.

The possibility of water pollution from the phosphate itself is minimized by the fact that the phosphate ore is quite insoluble as shown by water quality analyses on surface water in the area. The mining operation would not increase the soluble phosphate content of the water resource. The effectiveness of erosion control measure applied within the mining area will determine the quantity of particulate phosphate mineral and other sediments added to Sespe Creek. The liquid chemicals handled at the plant are to be confined within dikes. Except for possible leakage from these dikes, or in case of spills on the highway, water pollution from processing chemicals and products should not occur.

Increased soil erosion and related sediment load to stream channels will depend upon the manner in which the stream channels crossing the ore body are protected from the open-pit mining operation.

Some level of air pollution is possible from noxious gases emanating from the plant in the form of fluorine from the ore, $\mathrm{SO}_{2}$ gas from the manufacture of sulphuric acid, and fuel combustion products. Blasting, drilling, and equipment noise will have some environmental impact. Mining equipment will be diesel-powered and controlled by conventional mufflers.

The power requirements of the plant are estimated at 5,000 KVA. The mine would require the construction of 14 miles of transmission lines which is to be erected on wooden poles on the right-of-way of State Highway 33. Natural gas would be taken from a pipeline already in the area which passes within 3 miles of the proposed plant site using either overhead or buried lines.

The impact on vegetation and wildlife is influenced by the fact that, over the life of the mine, only 400 acres will be subjected to actual mining. The mining operation would involve an annual excavation of 4 to 5 acres with reclamation following closely in the mined-out area. A total of about 40 acres thus would be disturbed at any given time.

The brief summary above shows the main aspects of the planned mining operation for which environmental impact is being evaluated. More details on these and other aspects of the area and the project plan are contained in the company's report.

Using material contained in the company's report, an information matrix analysis was completed in the manner described in the previous section of this circular. The outcome of the analysis is recapitulated in reduced form as figure 2. The explanations which follow indicate the reasoning followed in this example.

The mining plan calls for a small "alteration of drainage" so that effects on "erosion" and "sedimentation" should be minor as compared with the effect of "highways and bridges" and "emplacement of tailings." "Modification of habitat" and "alteration of ground cover" are not likely to be important impacts because the total mined area is relatively small. "Industrial buildings" and "construction of highways" are considered to be among the more important impacts. The "blasting and drilling" under "construction" (II. B. q.) will be short term and have limited impact, but "drilling and blasting" for "resource extraction" (II. C. a.) will continue sporadically over the life of the project and, therefore, is relatively important. "Surface excavation" and "mineral processing" appear to have relatively important impact potential. On detailed consideration, "product storage" and "erosion control" are viewed as less important than some of the construction and resource extraction items noted above. Changes in traffic owing to the increase in "trucking" rather than increase in "automobile traffic" is considered to be capable of producing important impact. The 


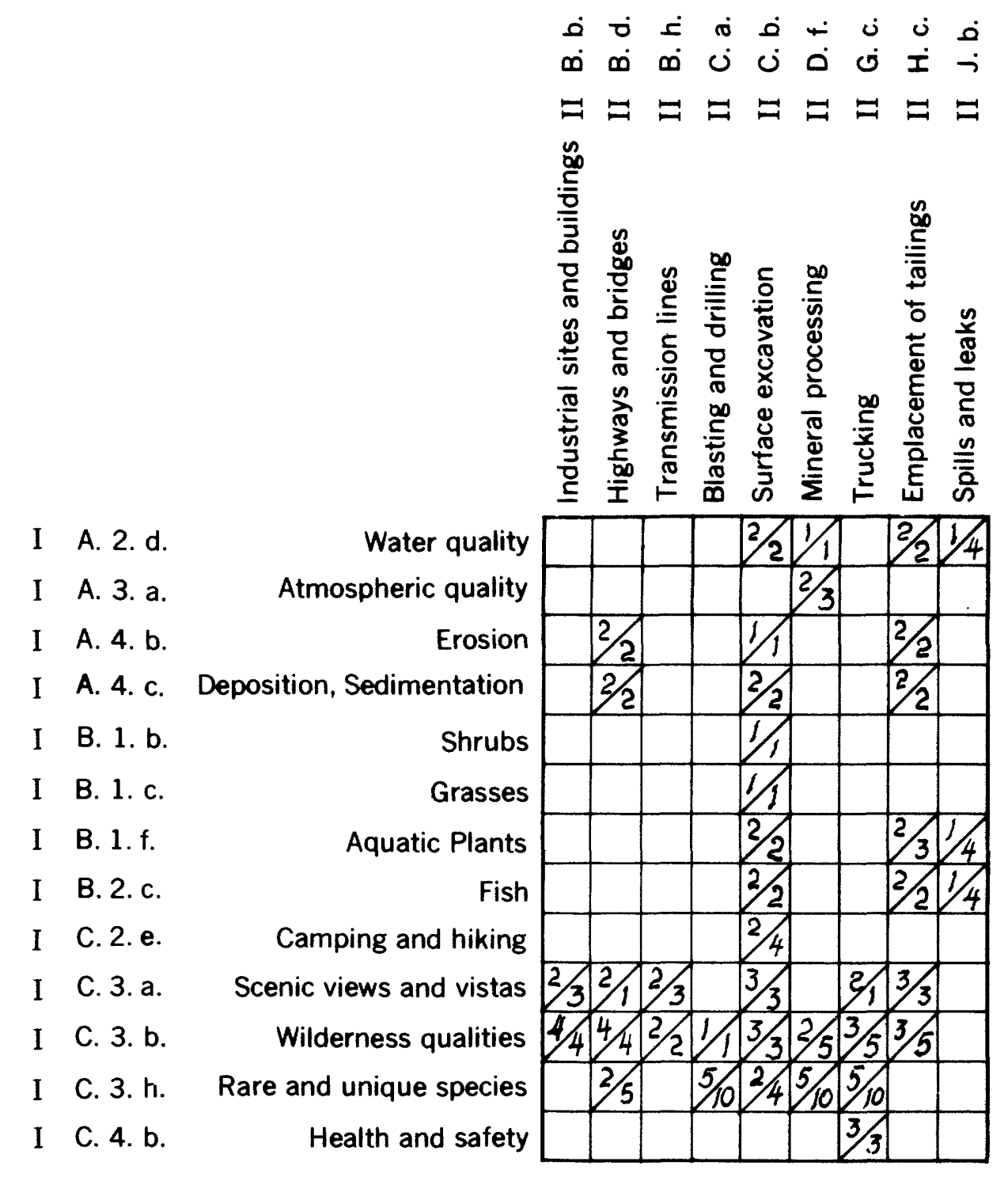

FIGURE 2.-The reduced matrix for a phosphate mining lease.

"emplacement of tailings" would occur through the life of the project and could have significant effects if poorly controlled. "Liquid effluent discharge" would be small during all phases of the project, and, therefore, would be relatively unimportant by comparison. "Spills and leaks" owing to accidents could be important within the mining operation area depending on the effectiveness of diking. Accidents would be especially significant on the highways over which new materials and finished products must be hauled.

With such consideration, the number of proposed actions considered important enough for discussion was reduced to 9 . Under each of these items in the vertical column existing characteristics and conditions of the environment were inspected individually. Where the interaction was deemed sufficiently important, the impact was numerically evaluated in terms of magnitude and importance. The resulting codification appears in the completed matrix (fig. 2). The types of impact are discussed below in order of the items listed on the lefthand side of figure 2 .

Water quality (I. A. 2. d.).-Water quality could be affected by the "surface excavation," by "emplacement of tailings," and by the pos- 
sibility of "accidental spills and leaks." The planned "surface excavation" is off-channel and was, therefore, assigned magnitude 2 . Because of the ephemeral nature of the streams, the importance of the excavation in affecting water quality was rated 2 also.

The same reasoning applies to the "emplacement of tailings" which are off-channel and not of a noxious character. "Spills and leaks" were considered sufficiently rare to be assigned magnitude 1 , but if they occurred, they would be moderately important and, therefore, given a value of 4 .

In actual practice, any of the identified impacts can be expanded to produce secondary matrices which can cover greater detail than is possible on plate I or figure 2 if the analysts or reviewer feels the need to do so. As an example, expanding the matrix items related to "water quality," the relative magnitude and importance of different specific actions may be more clearly shown than by merely using the main headings in the matrix. The example (fig. 3) indicates how expansion may show details pertinent to the individual situation. Additionally, water quality could also be expanded into subcategories such as $\mathrm{pH}$, dissolved oxygen, turbidity, etc.

Atmospheric quality (I. A. 3. a.).-_Mineral processing" would be the principal source of degradation in atmospheric quality. Its magnitude was rated 2 owing to the small size of the plant and the absence of other industrial operations. Its importance, however, was rated 3 because of the sulphuric nature of the gases produced.

Erosion (I. A. 4. b.) and deposition (I. A. 4. c.).-Some "erosion" and thus some channel "deposition" will be caused by the construction of "highways and bridges" and by the "emplacement of tailings." The sandy nature of the washes in the area and thus naturally high sediment loads give both "erosion" and "deposition" caused by the project a relatively low importance. The magnitude and importance of each were relatively low owing to the fact that the mining operation would involve the construction of less than 2 miles of new roads and that protection against erosion is included in the design of the mining operation.

Shrubs (I. B. 1. b.) and grasses (I. B. 1 . c.).-The disturbance of native "shrubs" and "grasses" is important only on the area which is going to be physically disturbed by the mining. Because vegetation change would occur only on parts of the 2,434 acre lease over the life of the project and revegetation is part of the scheduled project, the magnitude and importance are both rated low.

Aquatic plants (I. B. 1. f.).- "Aquatic plants" do not occur in the ephemeral streams near the plant site but do occur in the portion of the main stream some miles down valley where Sespe Creek is perennial. Any effect on "aquatic plants" reaching that far downstream would come from "excavation" and from "emplacement of tailings." The distance to the perennial stream indicated low values for magnitude, but a moderate value for importance in the case of "spills."

Fish (1. B. 2. C.).-The same reasoning that governed the assessment of impact on "aquatic plants" applies also to "fish" which persists only some miles downstream where Sespe Creek is perennial and the probable impacts are rated low.

Camping and Hiking (I.C. 2. e.).-The only alteration involving "camping and hiking" is caused by "surface excavation." Owing to the small area to be affected, its magnitude is rated 2 , but its importance was considered moderate and rated 4 because any environmental change that interrupts recreational use of public land in a highly populated State is relatively important.

Scenic Views and Vistas (II. C. 3. a.).-This is one of the characteristics that is most seriously impacted by the proposed development. "Scenic views" are impaired in quality owing to "industrial buildings," "highways and bridges," "transmission lines," "surface excavation," "trucking," and "emplacement of tailings." All these have a low to moderate value of magnitude and generally a somewhat higher figure for importance. Compared with any of the previous items, the actions impacting "scenic views and vistas" are more numerous. 


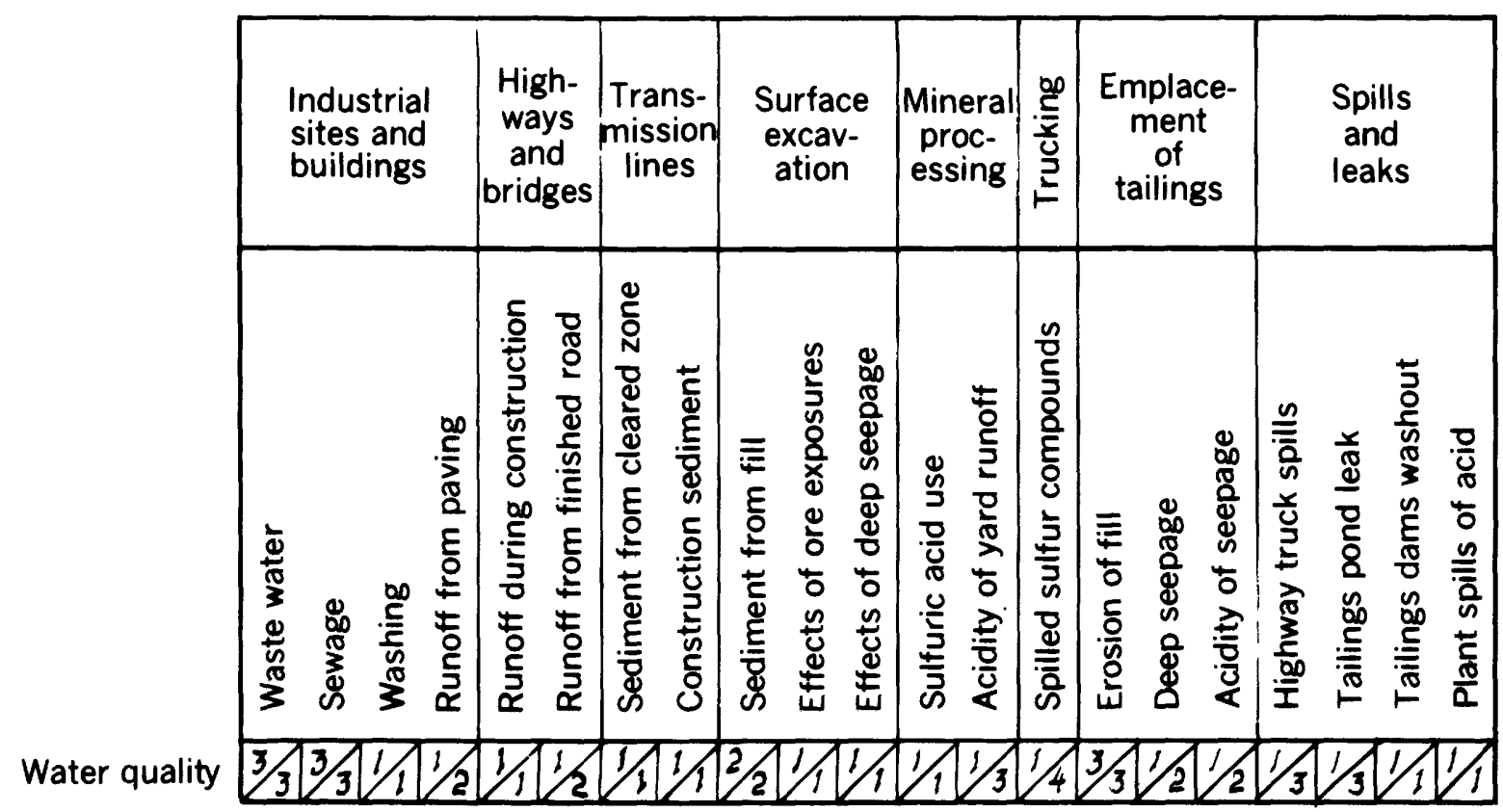

FIGURE 3.-Expanded matrix showing actions which would impact water quality.

Wilderness qualities (I. C. 3. b.).-The item "wilderness and open space" (I. B. 1. a.) as a land use is not important in this area because it is not designated wilderness; accordingly, it was not rated. What is important is the aesthetic and human interest item-"wilderness qualities." Thus, a distinction is made between wilderness as a "land use," not important in this area, and the "quality" of wild land which is considered highly important in the area. "Wilderness qualities" would be impacted under the proposed project primarily by "industrial buildings," "highways and bridges," "surface excavation," "trucking," and "emplacement of tailings." The impact of each on "wilderness qualities" is rated moderate with respect to both magnitude and imporance. The result of this is that the degradation of "wilderness qualities" may be considered a potentially important impact caused by the proposed development.

Rare and unique species (I. C. 3. h.).-Possibly the most important environmental impact of the proposed development is its potential effect on the condor. A distinction is made between the biological conditions of fauna, "endangered species" (I. B. 2. g.), and the item under "aesthetics and human interest," "rare and unique species." The condor could be covered under either of these two, but should not be under both. As a matter of choice then, the condor problem is specified under the item of "aesthetics and human interest."

Consideration was given to the fact that the main nesting area for the condors is some miles to the southeast and that a Naval training camp involving much heavy equipment is already operating near that nesting area. It is believed that the effect of the proposed development on condors would come about primarily from the "blasting" and from the increase in "truck traffic." For both of these actions, the magnitude is considered moderate and rated 5, but the importance of the survival of condors was considered to be great and thus any impact is of high importance. Those two items were, therefore, given an importance score of 10 . Also the sulphur fumes from "mineral processing" might be an important deterrent to the use of this part of the range by condors. The effect on the birds is unknown, but it is conceivable that air pollution would keep them from landing to catch prey wherever the smell and smoke occurred. The magnitude of impact of this ac- 
tion was assessed as 5 and importance as 10.

Health and safety (I. C. 4. b.).-_"Health and safety" would be impacted primarily by the increase in "trucking" on the highway as a result of mine operation.

Summary.-Inspection of figure 2 immediately gives the essence of the matrix analysis: the proposed actions which have the most environmental impacts are the construction of "highways and bridges," the "blasting," "surface excavation," "mineral processing," "trucking," and the "emplacement of tailings." The enviromental characterisitcs most frequently impacted are those of "scenic views and vista," "wilderness qualities," and "rare and unique species."

As an outcome of this matrix analysis, the reviewers could ask the petitioners for the phosphate project "What actions can you take to reduce these possible impacts to lower levels?" if the impact is deemed sufficiently great. As an example, assume that the company, in light of the comparative values shown in the simplified matrix, decided to substitute for daytime trucking, a night-time only schedule for moving supplies and products. If it were known that condors soar only during the day and would be unaffected by night-time traffic, that magnitude-importance impact might be significantly reduced. Assume also that as another step to reduce impact, the company decided to mat the ground surface prior to any rock blasting. If this step were deemed effective, matrix entry of $5 / 10$ of blasting on rare and unique species might perhaps reduce the entry at $1 / 10$. These changes may, in one sense, appear to be minor, but in fact would cause a significant reduction in impact on the specific environmental factor shown to be most affected.

\section{REFERENCES}

Council on Environmental Quality, 1971, Statements on proposed Federal actions affecting the environment: Federal Register, v. 36, no. 19, p. 13981402 and no. 79, p. 7724-7729.

Gillette, Robert, 1971, Trans-Alaska pipeline: Impact Study Receives Bad Reviews: Science, v. 171, Mar. 19.

Sorensen, J. C., 1971, A framework for identification and control of resource degradation and conflict in the multiple use of the coastal zone: Univ. of Calif., Berkeley, Dept. of Landscape Architecture, M. S. thesis, p. 42; in press, Univ. of Calif. Press. (Contains a state-of-the-art review of matrix use in environmental studies) 